06

\title{
Влияние начальной температуры на процесс проникания ударников из пористого сплава на основе вольфрама с упрочняющим наполнителем в стальную преграду
}

\author{
(C) А.Н. Ищенко, С.А. Афранасьева, Н.Н. Белов, В.В. Буркин, В.З. Касимов, Л.С. Марцунова, К.С. Рогаев, \\ А.Ю. Саммель, А.Б. Скосырский, Н.Т. Югов
}

Научно-исследовательский институт прикладной математики и механики Национального исследовательского Томского государственного университета, 634050 Томск, Россия

e-mail: s.a.afanasyeva@mail.ru

Поступило в Редакцию 22 марта 2019 г.

В окончательной редакции 16 декабря 2019 г.

Принято к публикации 16 декабря 2019 г.

\begin{abstract}
Продолжена серия исследований, направленных на изучение особенностей и выявление общих закономерностей проникающей способности ударников из композиционного материала на основе пористого сплава вольфрам + никель + железо + кобальт с добавлением высокотвердых тугоплавких частиц карбида титана вольфрама при различных начальных условиях. В частности, изучено влияние начальной температуры ударника в интервале от -50 до $50^{\circ} \mathrm{C}$ на процесс проникания в стальную преграду экспериментальным и расчетным способом. Выявлено отсутствие заметного влияния начальной температуры ударника в данном интервале на глубину проникания в преграду при скоростях удара до $2500 \mathrm{~m} / \mathrm{s}$. Наблюдается превышение проникающей способности на 20\% по сравнению с монолитным массогабаритным аналогом из сплава ВНЖ-90.
\end{abstract}

Ключевые слова: композиционный материал, ударник, глубина проникания, температура, экспериментальное, математическое моделирование.

DOI: 10.21883/JTF.2020.05.49183.102-19

\section{Введение}

В последнее время наблюдаются возрастающие интересы к разработке перспективных материалов и исследованию их физико-механических и функциональных свойств для условий высокоскоростного удара. Целенаправленные исследования тяжелых вольфрамовых сплавов для сердечников перспективных бронебойных снарядов [1-4] направлены на получение высокоплотных образцов путем консолидации порошковых композиций в различных технологических режимах и применения специальных термомеханических обработок. Как отмечено [1], эффективность бронепробития ударниками зависит не только от их прочностных характеристик, но и от механизма разрушения в процессе взаимодействия с преградой. Исследования высокоскоростного проникания ударников из композиционного материала на основе сплава вольфрам + никель + железо + кобальт (ВНЖК) с высокотвердыми легирующими добавками типа карбидов вольфрама, не отличающихся максимальными прочностными свойствами, рассматриваются в [5]. Композиционные ударники из пористого сплава ВНЖК + 10 wt.\% карбида титана вольфрама (TiWC) показали существенное превышение глубины проникания по сравнению с массогабаритным аналогом из монолитного сплава ВНЖ-90 при скорости удара порядка 2800 m/s.
Продолжением этих исследований является рассмотренное в настоящей работе влияние начальной температуры ударника из пористого сплава $\left(\right.$ ВНЖК +10 wt.\% TiWC) в интервале -50 до $50^{\circ} \mathrm{C}$ на процесс проникания в стальную преграду экспериментальным и расчетным способами.

Экспериментальные исследования глубины проникания проведены на лабораторном баллистическом стенде [6]. Математическое моделирование проведено в рамках модели пористой упругопластической среды [7], модифицированной для описания поведения материалов на основе сплава ВНЖК с высокотвердыми легирующими добавками [8] с возможностью оценки температуры в процессе взаимодействия. Расчеты проведены с помощью программного комплекса [9].

\section{Расчет температуры при высокоскоростном соударении}

Для оценки температуры при взаимодействии многокомпонентных сред (в нашем случае сплавы $($ ВНЖК + 10 wt.\% TiWC)) в математической модели [7] в качестве уравнения состояния используется уравнение Ми-Грюнайзена. При линейной зависимости скорости ударной волны от массовой скорости $u$ на ударной адиабате, $D=c_{m 0}+S_{m 0} u$, которая выполняется для многих конструкционных материалов, уравнение состояния 
имеет вид [10]:

$$
p(v, \varepsilon)=\left(A \mu+B \mu^{2}+C \mu^{3}+\gamma_{m 0} \rho_{m 0} \varepsilon\right) / \alpha,
$$

где $v$ - удельный объем пористой среды, $\varepsilon-$ удельная внутренняя энергия, $\rho_{m 0}$ - начальная плотность материала матрицы, $\gamma_{m 0}$ - коэффициент Грюнайзена материала матрицы, $\alpha=v / v_{m}, v_{m}$ - удельный объем материала матрицы, $\mu=\alpha / \rho_{m 0} v-1$,

$$
A=B_{m 0}=\rho_{m 0} c_{m 0}^{2}
$$

- модуль объемного сжатия,

$$
\begin{gathered}
B=B_{m 0}\left[\left(1-\gamma_{m 0} / 2\right)+2\left(S_{m 0}-1\right)\right], \\
C=B_{m 0}\left[2\left(1-\gamma_{m 0} / 2\right)\left(S_{m 0} u-1\right)+3\left(S_{m 0}-1\right)^{2}\right] .
\end{gathered}
$$

Если в качестве опорной кривой для уравнения (1) взять изэнтропу, проходящую через начальное состояние $\left(p_{m}=0, T=T_{0}, v_{m}=v_{m 0}, \varepsilon\left(v_{m 0}, T_{0}\right)=0\right)$, то холодная составляющая энергии выражается как

$$
\varepsilon_{x}=\varepsilon_{00}+\varepsilon_{01} \eta+\varepsilon_{02} \eta^{2}+\varepsilon_{03} \eta^{3}+\varepsilon_{04} \eta^{4},
$$

где

$$
\begin{gathered}
\eta=1-\rho_{m 0} v / \alpha, \varepsilon_{00}=-T_{0} c_{v}, \varepsilon_{01}=\varepsilon_{00} \gamma_{m 0}, \\
\varepsilon_{02}=1 / 2\left(c_{m 0}^{2}+\gamma_{m 0}^{2} \varepsilon_{00}\right), \varepsilon_{03}=1 / 6\left(4 S_{m 0} c_{m 0}^{2}+\gamma_{m 0}^{3} \varepsilon_{00}\right), \\
\varepsilon_{04}=1 / 2\left(-2 \gamma_{m 0} S_{m 0} c_{m 0}^{2}+18 S_{m 0}^{2} c_{m 0}^{2}+\gamma_{m 0}^{4} \varepsilon_{00}\right),
\end{gathered}
$$

$c_{v}$ - удельная теплоемкость материала, $T_{0}$ - начальная температура $[\mathrm{K}]$.

Тогда можно определить температуру в твердом теле из соотношения

$$
\begin{aligned}
T(v, \varepsilon)= & {\left[\varepsilon-\varepsilon_{00}-\varepsilon_{01} \mu+\left(\varepsilon_{02}--\varepsilon_{01}\right) \mu^{2}-\left(\varepsilon_{01}-2 \varepsilon_{02}\right.\right.} \\
& \left.\left.+\varepsilon_{03}\right) \mu^{3}-\left(3 \varepsilon_{02}-3 \varepsilon_{03}+\varepsilon_{04}--\varepsilon_{01}\right) \mu^{4}\right] / c_{v} .
\end{aligned}
$$

Удельная теплоемкость химического соединения при нормальных условиях определяется как $c_{v}=3 n R / N a M m_{\mathrm{H}}$, где $R-$ универсальная газовая постоянная, $n$ - число атомов в соединении, $\mathrm{Na}$ число Авогадро, $M$ - молярный вес, $m_{\mathrm{H}}-$ масса атома водорода. Удельная теплоемкость многокомпонентной системы определяется как $c_{v}=\Sigma c_{v i} m_{i}$, где $c_{v i}, m_{i}-$ удельная теплоемкость и массовая доля $i$-ой компоненты соответственно.

На основании данных [11-13] определены удельные теплоемкости исследуемых материалов при различных начальных температурах (табл. 1).

Параметры математической модели пористого сплава (ВНЖК + 10 wt.\% TiWC) и стали приведены в табл. 2, где обозначено: $\rho_{m 0}, c_{m 0}, S_{m 0}, \gamma_{m 0}, \mu_{m 0}, \sigma_{m s}-$ плотность, объемная скорость звука, коэффициент наклона ударной адиабаты, коэффициент Грюнайзена, модуль сдвига и динамический предел текучести материала матрицы соответственно, $a_{s}, \alpha_{00}, \xi^{*}, e_{u}^{*}-$ константы модели разрушения материала.

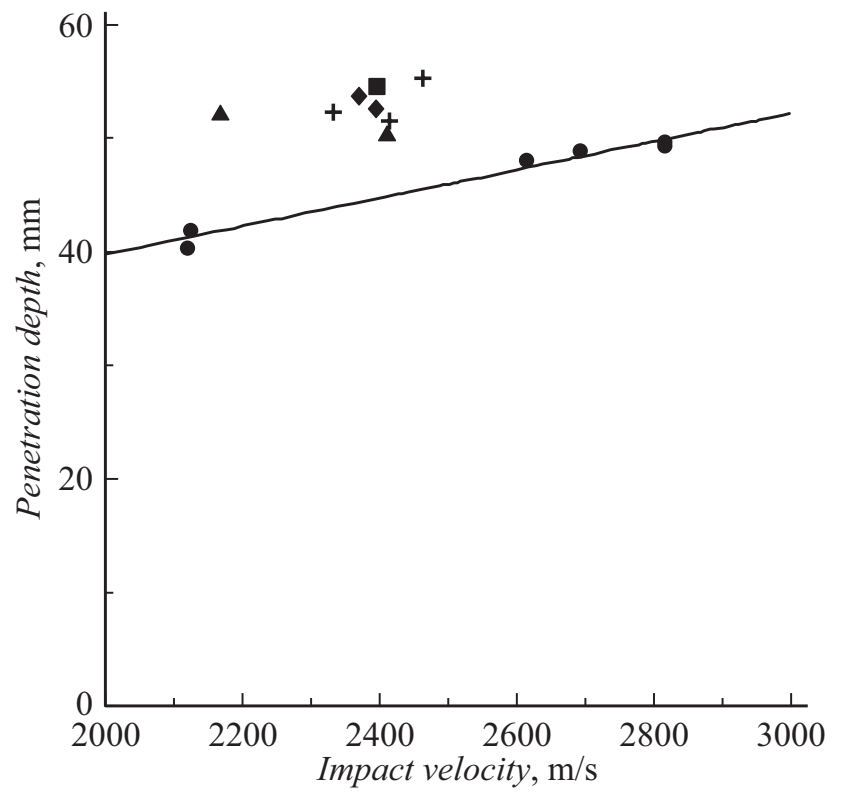

Рис. 1. Глубина проникания ударников из сплава ВНЖК + 10 wt.\% TiWC в стальную преграду: $T_{0},{ }^{\circ} \mathrm{C}:+-50$, $\checkmark-20, \boldsymbol{\square}-30, \boldsymbol{\Delta}-50, \bullet-$ ВНЖ-90 при $T_{0}=20^{\circ} \mathrm{C}$.

\section{Результаты экспериментально-теоретических исследований}

Для баллистических испытаний методом высокотемпературного спекания были изготовлены цилиндрические ударники из сплава (ВНЖК $+10 \mathrm{wt} . \%$ TiWC) массой $m=30 \mathrm{~g}$ и диаметром $d=9 \mathrm{~mm}$. Исходная плотность порошковых компонент: ВНЖК составляет $16.25 \mathrm{~g} / \mathrm{cm}^{3}$, TiWC $-10.91 \mathrm{~g} / \mathrm{cm}^{3}$. Теоретическая плотность сплава (ВНЖК + 10 wt.\% TiWC) составляет $\rho_{m 0}=16.23 \mathrm{~g} / \mathrm{cm}^{3}$. В процессе консолидации порошковых компонентов при ВТС сохраняется остаточная пористость, в связи с чем ударники могут иметь различную начальную плотность $\rho_{0}$. В табл. 3 приведены средние значения физико-механических характеристик образцов материала. Объем пустот в образцах материала $\xi=\left(1-\rho_{0} / \rho_{m 0}\right) \cdot 100$ в среднем равен $20 \%$.

$\mathrm{C}$ целью исследования влияния начальной температуры на процесс высокоскоростного проникания ударников из пористого сплава (ВНЖК + 10 wt.\% TiWC) в стальную преграду толщиной $87 \mathrm{~mm}$ проведены баллистические испытания при начальной температуре ударников $T_{0}$ в интервале от -50 до $50^{\circ} \mathrm{C}$ при скоростях удара $V_{0}$ в диапазоне $2100-2500 \mathrm{~m} / \mathrm{s}$. На рис. 1 приведены результаты эксперимента. Там же для сравнения приведена зависимость глубины проникания массогабаритного аналога из монолитного сплава ВНЖ-90.

Результаты эксперимента демонстрируют отсутствие зависимости глубины проникания от начальной температуры испытуемых ударников в рассматриваемом диапазоне. При этих условиях наблюдается 

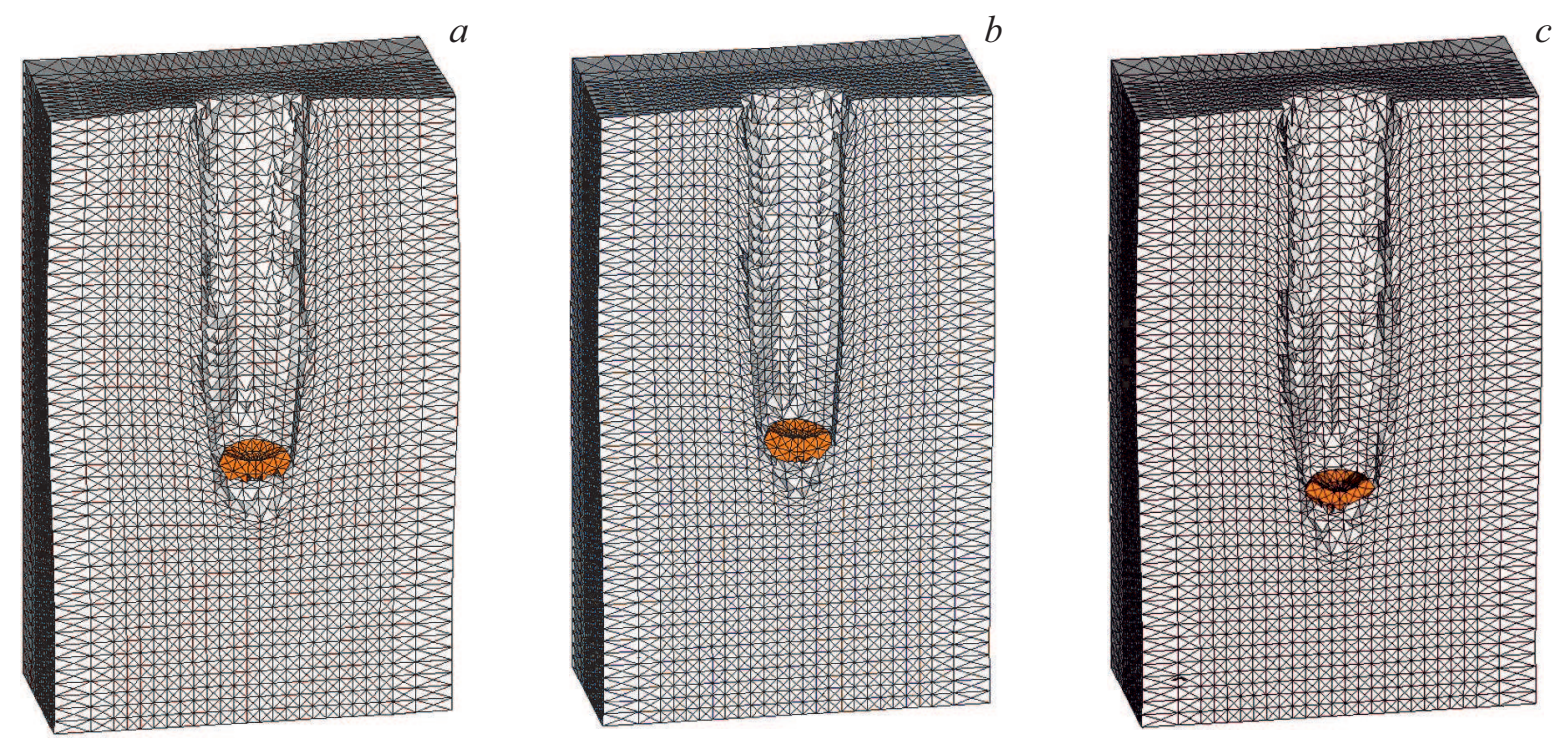

Рис. 2. Вид кратера и остатка ударника из сплава ВНЖК $+10 \mathrm{wt} . \%$ TiWC после соударения: $a-$ опыт $1, t=86 \mu \mathrm{s}, b-$ опыт 2 , $t=90 \mu \mathrm{s}, c-$ опыт $3, t=90 \mu \mathrm{s}$.

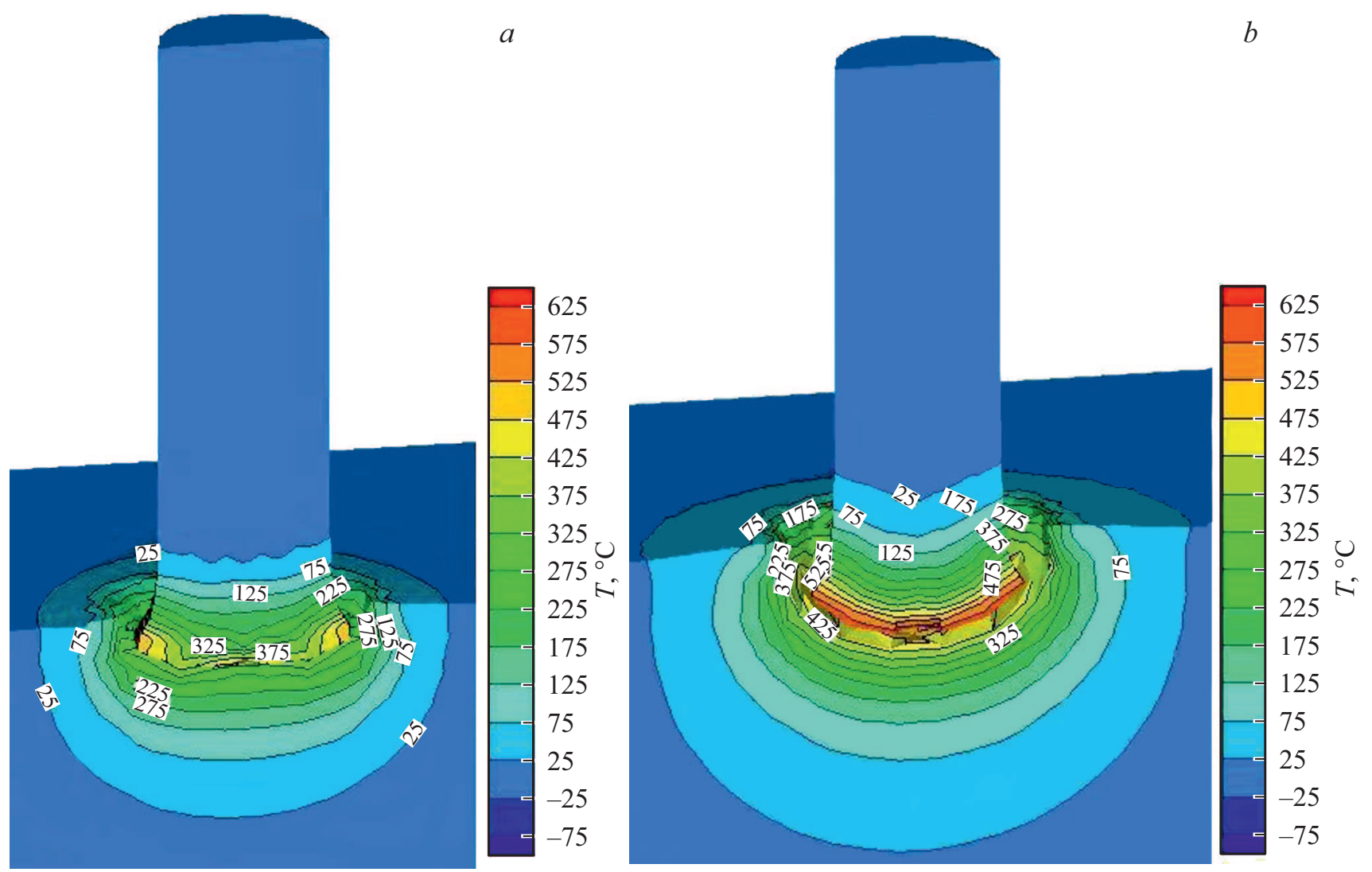

Рис. 3. Распределение температуры в зоне взаимодействия ударника из сплава ВНЖК +10 wt.\% ТiWC со стальной преградой при $V_{0}=2395 \mathrm{~m} / \mathrm{s}, T_{0}=20^{\circ} \mathrm{C}: a-t=2, b-t=4 \mu \mathrm{s}$.

превышение глубины проникания ударников сплава (ВНЖК + 10 wt.\% TiWC) в среднем на 20\% по сравнению с массогабаритным аналогом из сплава ВНЖ-90, что подтверждает полученные ранее результаты $[5,8]$.
Условия опытов при заданных начальной температуре ударников из сплава (ВНЖК $+10 \mathrm{wt} . \%$ TiWC) и скорости удара $V_{0}$ повторены при математическом моделировании. В табл. 4 и на рис. 2 приведены 


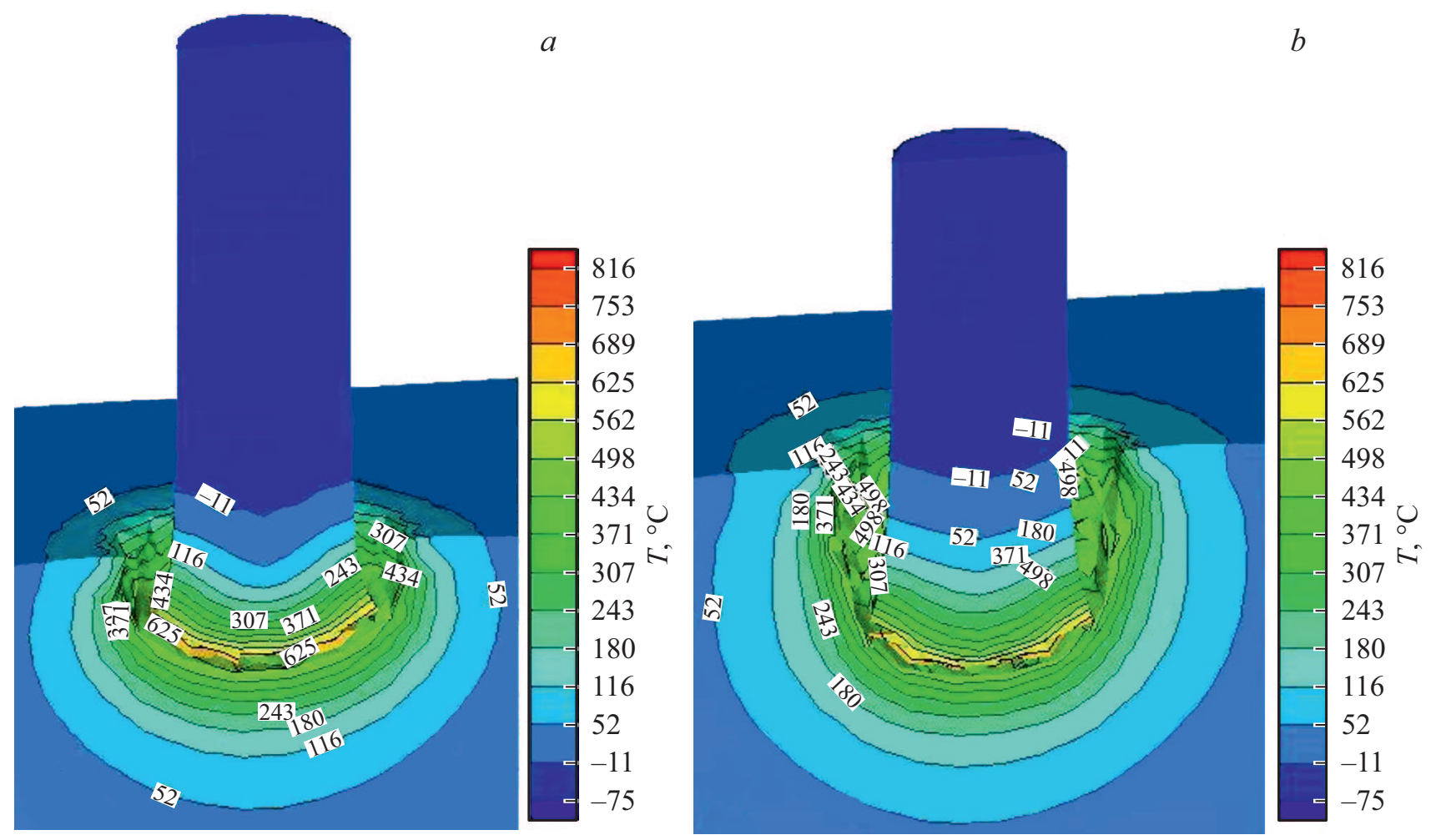

Рис. 4. Распределение температуры в зоне взаимодействия ударника из сплава ВНЖК $+10 \mathrm{wt} . \%$ TiWC со стальной преградой при $V_{0}=2167 \mathrm{~m} / \mathrm{s}, T_{0}=-50^{\circ} \mathrm{C}: a-t=5, b-t=10 \mu \mathrm{s}$.

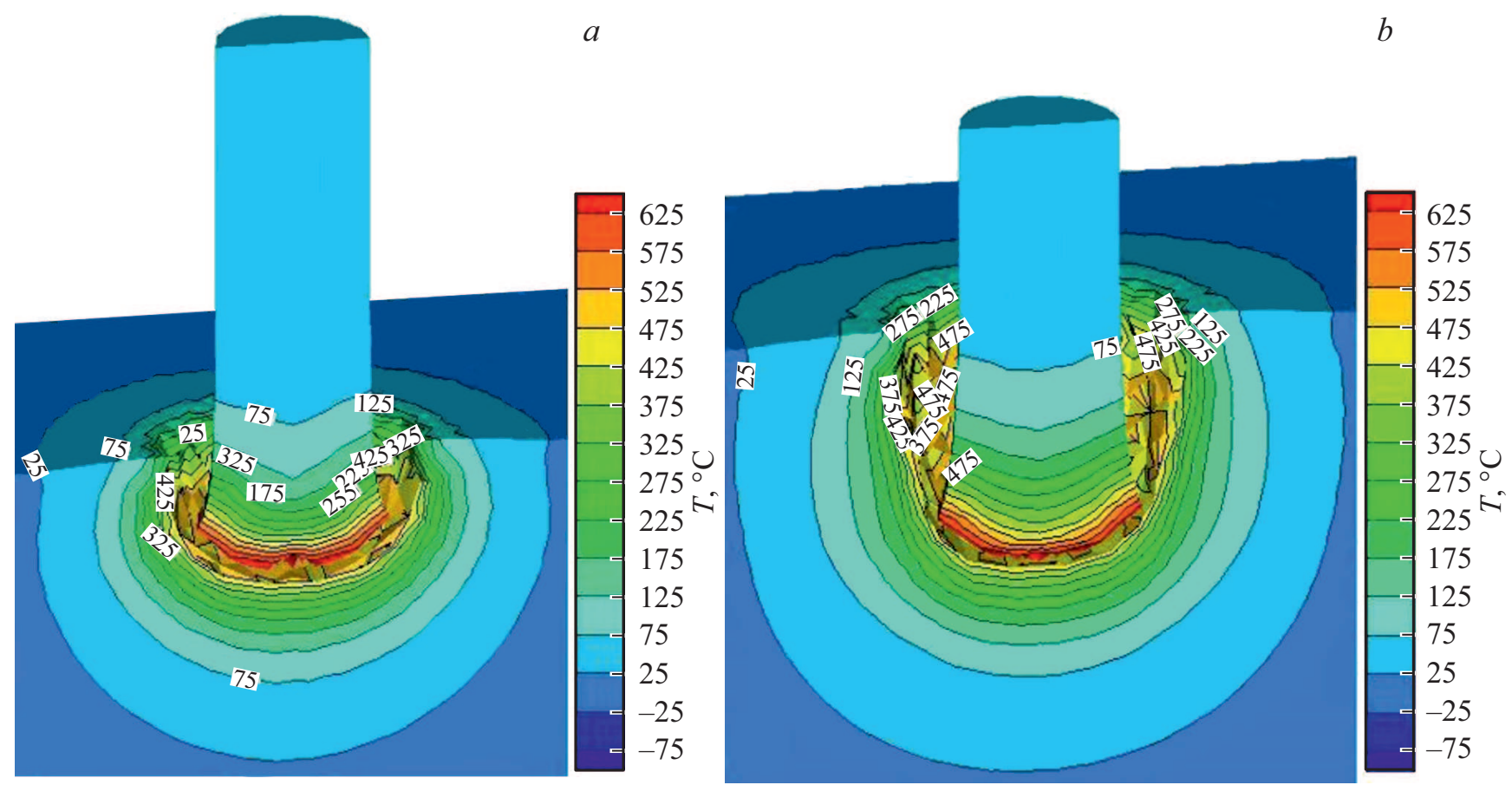

Рис. 5. Распределение температуры в зоне взаимодействия ударника из сплава ВНЖК $+10 \mathrm{wt} . \%$ TiWC со стальной преградой при $V_{0}=2463 \mathrm{~m} / \mathrm{s}, T_{0}=50^{\circ} \mathrm{C}: a-t=5, b-t=10 \mu \mathrm{s}$.

результаты расчетов на момент времени $t$ окончания процесса проникания. Расхождение результатов расчета с экспериментом $\Delta$ по глубине кратера $h$ в среднем составляет $3 \%$. 
Таблица 1. Удельная теплоемкость исследуемых материалов

\begin{tabular}{c|c|c|c|c|c|c}
\hline Материал & $T_{0},{ }^{\circ} \mathrm{C}$ & $c_{v}, \mathrm{~J} /(\mathrm{kg} \cdot \mathrm{K})$ & $T_{0},{ }^{\circ} \mathrm{C}$ & $c_{v}, \mathrm{~J} /(\mathrm{kg} \cdot \mathrm{K})$ & $T_{0},{ }^{\circ} \mathrm{C}$ & $c_{v}, \mathrm{~J} /(\mathrm{kg} \cdot \mathrm{K})$ \\
\hline ВНЖК + 10 wt.\% TiWC & -50 & 158.5 & 20 & 179.16 & 50 & 180.44 \\
Сталь & -50 & 360 & 20 & 468 & 50 & 459
\end{tabular}

Таблица 2. Параметры математической модели исследуемых материалов

\begin{tabular}{c|c|c|c|c|c|c|c|c|c|c}
\hline Материал & $\rho_{m 0}, \mathrm{~g} / \mathrm{cm}^{3}$ & $c_{m 0}, \mathrm{~cm} / \mu \mathrm{s}$ & $S_{m 0}$ & $\gamma_{m 0}$ & $\mu_{m 0}, \mathrm{GPa}$ & $\sigma_{m s}, \mathrm{GPa}$ & $a_{s}, \mathrm{GPa}$ & $\alpha_{00}$ & $\xi^{*}$ & $e_{u}^{*}$ \\
\hline ВНЖK+10 wt.\% TiWC & 16.23 & 0.42 & 1.167 & 1.61 & 144.73 & 1.464 & 0.966 & 1.0008 & 0.3 & 1.0 \\
Сталь & 7.85 & 0.457 & 1.49 & 2.26 & 82.0 & 1.0 & 0.66 & 1.0006 & 0.03 & 1.0
\end{tabular}

Таблица 3. Физико-механические характеристики образцов из сплава (ВНЖК + 10 wt.\% TiWC)

\begin{tabular}{c|c|c|c|c}
\hline Начальная плотность, g/sm & $\begin{array}{c}\text { Предел прочности } \\
\text { при растяжении, МРа }\end{array}$ & $\begin{array}{c}\text { Предел прочности } \\
\text { при сжатии, МРа }\end{array}$ & Твердость, НRА & Модуль Юнга $E$, МРа \\
\hline 13 & 294 & 1328 & 67.7 & 20661
\end{tabular}

Таблица 4. Результаты математического моделирования

\begin{tabular}{c|c|c|c|c|c}
\hline Опыт & $\rho_{0}, \mathrm{~g} / \mathrm{cm}^{3}$ & $T_{0},{ }^{\circ} \mathrm{C}$ & $V_{0}, \mathrm{~m} / \mathrm{s}$ & $h, \mathrm{~mm}$ & $\Delta, \%$ \\
\hline 1 & 12.91 & 20 & 2395 & 53.28 & 2.3 \\
2 & 13.14 & -50 & 2167 & 51.36 & 1.4 \\
3 & 13.44 & 50 & 2463 & 55.33 & 5.0
\end{tabular}

На рис. 3-5 приведены фрагменты зоны взаимодействия ударника и преграды в начальной стадии в виде уровней температуры $\left[{ }^{\circ} \mathrm{C}\right]$. Во всех вариантах расчета наибольшая температура сосредоточена в зоне контакта ударника и преграды и практически на порядок превышает начальные значения, причем во время взаимодействия зона высоких температур быстро распространяется вслед за ударными волнами по ударнику и преграде, что нивелирует влияние начального состояния. Таким образом, в рассматриваемом диапазоне начальная температура ударника практически не влияет на глубину проникания ударника в преграду при рассмотренных скоростях соударения.

\section{Заключение}

Выполнены расчетно-экспериментальные исследования проникания ударника из пористого сплава (BНЖK + 10 wt.\% TiWC) в стальную преграду при начальных температурах ударника в диапазоне от -50 до $50^{\circ} \mathrm{C}$ при скоростях соударения $2100-2500 \mathrm{~m} / \mathrm{s}$.

Усовершенствована методика математического моделирования $[7,8]$ для расчета поля температур при взаимодействии ударника из многокомпонентного материала, каким является сплав (ВНЖК $+10 \mathrm{wt} . \%$ TiWC), с преградой.
Установлено отсутствие влияния начальной температуры ударника из сплава (ВНЖК + 10 wt.\% TiWC) на глубину проникания в стальную преграду в рассматриваемом диапазоне исходных параметров.

Наблюдается превышение проникающей способности ударников из сплава (ВНЖК + 10 wt.\% TiWC) в стальную преграду по сравнению с массогабаритным аналогом из сплава ВНЖ-90.

\section{Благодарности}

В работе использованы результаты, полученные в ходе выполнения проекта № 8.2.09.2018 Программы повышения конкурентоспособности Национального исследовательского Томского государственного университета.

\section{Конфликт интересов}

Авторы заявляют, что у них нет конфликта интересов.

\section{Список литературы}

[1] Поварова К.Б., Алымов М.И., Гаврилин О.С., Дроздов А.А., Евстратов Е.В., Качнов А.И., Салько А.Е. // Металлы. 2007. № 6. С. 65-72.

[2] Поварова К.Б., Алымов М.И., Дроздов А.А. // Вопросы материаловедения. 2008. № 2 (54). С. 94-99.

[3] Черняк Г.Б., Поварова К.Б. Вольфрам в боеприпасах. Научное издание. / Под ред. И.Н. Торгуна. М.: ЦНИИХМ, 2014. $360 \mathrm{c}$.

[4] Брагов А.М., Чувильдеев В.Н., Милехин Н.В., Филиппов А.Р., Константинов А.Ю., Сахаров Н.В. // Физическая мезомеханика. 2018. № 2 (21). С. 96-102. 
[5] Ищенко А.Н., Афанасьева С.А., Белов Н.Н., Буркин В.В., Рогаев К.С., Саммель А.Ю., Скосырский А.Б., Табаченко А.Н., Югов Н.Т. // Письма в ЖТФ. 2017. Т. 43. Вып. 17. C. 41-47.

[6] Бураков В.А., Буркин В.В., Ищенко А.Н., Корольков Л.В., Степанов Е.Ю., Чупашев А.В., Агафонов С.В., Рогаeв К.С. Экспериментальный баллистический комплекс. Патент на изобретение № 2591132 от 20.06.2016.

[7] Белов Н.Н., Демидов В.Н., Ефремова Л.В., Жуков А.В., Николаев А.П., Симоненко В.Г., Трушков В.Г., Хабибуллин М.В. Шиповский И.Е., Шуталев В.Б. // Изв. вузов. Физика. 1992. № 8. С. 5-48.

[8] Ищенко А.Н., Акиншин Р.Н., Афанасьева С.А., Белов Н.Н., Борисенков И.Л., Буркин В.В., Табаченко А.Н., Хабибуллин М.В., Югов Н.Т. // Изв. вузов. Физика. 2018. Т. 61. № 6. C. $49-55$.

[9] Югов Н.Т., Белов Н.Н., Югов А.А. Расчет адиабатических нестандартных течений в трехмерной постановке (РАНЕТ-3) / Федеральная служба по интеллектуальной собственности, патентам и товарным знакам. Свидетельство о государственной регистрации программ для ЭВМ № 2010611042. M. 2010.

[10] Gust W.H. // Y. Appl. Phys. 1982. Vol. 53. N 5. P. 3566-3575.

[11] Зиновьев В.E. Теплофизические свойства металлов при высоких температурах: справ. Изд-во Металлургия, 1989. $200 \mathrm{c}$.

[12] Чиркин В.С. Теплофизические свойства материалов ядерной техники. Справочник Изд-во Атомиздат, 1968. $721 \mathrm{c.}$

[13] Лариков Л.Н., Юрченко Ю.Ф. Тепловые свойства металлов и сплавов. Справочник. Киев: Наукова думка, 1985. $439 \mathrm{c}$. 